\title{
Elucidation of the reaction mechanism upon lithiation and delithiation of $\mathrm{Cu}_{0.5} \mathrm{TiOPO}_{4}^{\dagger} \uparrow$
}

Cite this: J. Mater. Chem. A, 2014, 2 , 12513

Received 3rd April 2014 Accepted 1st June 2014

DOI: $10.1039 / \mathrm{c} 4 \mathrm{ta0} 01627 \mathrm{k}$

www.rsc.org/MaterialsA

\begin{abstract}
Peter Bleith, ${ }^{\mathrm{a}}$ Maxence Valla, ${ }^{\mathrm{b}}$ Petr Novák ${ }^{\mathrm{a}}$ and Claire Villevieille ${ }^{\star a}$
The reaction mechanism of $\mathrm{Cu}_{0.5} \mathrm{TiOPO}_{4}$ upon lithiation and delithiation was elucidated by XAS, ${ }^{31} \mathrm{P}-\mathrm{NMR}$, $X R D, E D X$, and electrochemical methods. The material reacts with a combined insertion and conversion process, in which first copper is extruded irreversibly by forming $\mathrm{LiTiOPO}_{4}$. Afterwards, $\mathrm{Ti}^{4+}$ is reduced reversibly in an insertion reaction followed by a conversion reaction. The conversion reaction leads to amorphization of the sample while titanium is reduced to oxidation states below $2+$.
\end{abstract}

\section{Introduction}

Lithium-ion batteries are one of the most used electrochemical energy storage systems nowadays. In order to further improve the system, there is a constant search for new electrode materials, allowing a higher voltage or increasing the capacity of the cells. Some materials exhibit a high specific charge but react at potentials that are not useful in a full cell because using them results in less energy stored in the system. However, understanding such a reaction mechanism is crucial in the way of designing new materials with high specific charge reacting at a reasonable potential.

Metal titanium oxyphosphates, also called metal titanyl phosphates, $\left(\mathrm{M}_{0.5} \mathrm{TiOPO}_{4}\right.$ with $\mathrm{M}=\mathrm{Ni}^{2+}, \mathrm{Fe}^{2+}, \mathrm{Co}^{2+}, \mathrm{Cu}^{2+}$, and $\mathrm{Mg}^{2+}$ ) are a family of isostructural materials. In 2005, it was reported that $\mathrm{Ni}_{0.5} \mathrm{TiOPO}_{4}$ exhibits a quite high specific charge of $415 \mathrm{~A} \mathrm{~h} \mathrm{~kg}^{-1}$ which corresponds to a reaction with $\approx 3 \mathrm{Li}^{+}$per formula unit (f. u.) upon lithiation to $0.5 \mathrm{~V} v s . \mathrm{Li}^{+} / \mathrm{Li}$ and $\approx 2 \mathrm{Li}^{+}$ per f. u. upon delithiation to $4.0 \mathrm{~V} .^{1}$

In the following years, studies were ongoing to understand the reason for the high specific charge of $\mathrm{Li}_{2 x} \mathrm{Ni}_{0.5-x} \mathrm{TiOPO}_{4},{ }^{2-7}$ $\mathrm{Co}_{0.5} \mathrm{TiOPO}_{4},{ }^{8}$ and $\mathrm{Fe}_{0.5} \mathrm{TiOPO}_{4}{ }^{9}$ but none of these completely elucidated the reaction mechanism. For example, it is unclear at which potential and to which degree the M-atom is reduced upon lithiation and re-oxidized upon delithiation in different $\mathrm{M}_{0.5} \mathrm{TiOPO}_{4}$ : Belharouak and Amine claimed evaluating the $\mathrm{Ni}$

${ }^{a}$ Paul Scherrer Institut, Electrochemistry Laboratory, CH-5232 PSI Villigen, Switzerland. E-mail: Claire.Villevieille@psi.ch; Fax: +41 56310 2688; Tel: +41 56 3102410

${ }^{b}$ ETH Zürich, Laboratory of Inorganic Chemistry, Vladimir-Prelog-Weg 1, CH-8093 Zürich, Switzerland

$\dagger$ Electronic supplementary information (ESI) available: Refinement of the XRD of $\mathrm{Cu}_{0.5} \mathrm{TiOPO}_{4}$ cycled to $1.71 \mathrm{~V}$ (sample c). In situ XRD measurement of $\mathrm{Cu}_{0.5} \mathrm{TiOPO}_{4}$ cycled two times. Fit of the EXAFS data of $\mathrm{Cu}_{0.5} \mathrm{TiOPO}_{4}$ cycled to $1.78 \mathrm{~V}, 1.71 \mathrm{~V}$, and uncycled (samples a-c). The ${ }^{31} \mathrm{P}$ NMR spectrum of triphenyl phosphine. A table with calculated and experimental chemical shifts of triphenyl phosphine and LiTiOPO $_{4}$. See DOI: 10.1039/c4ta01627k
K-edge that $\mathrm{Ni}^{2+}$ remains unchanged ${ }^{1}$ but Hollmark et al. claimed by observing the $\mathrm{Ni}$ L-edge that $\mathrm{Ni}^{2+}$ is reduced upon lithiation to an oxidation state "somewhat below $\mathrm{Ni}^{1+}$ " and is not completely re-oxidised to $\mathrm{Ni}^{2+}$ upon delithiation. ${ }^{2}$ Essehli et al. did not detect any metallic Co upon lithiation using $\mathrm{XRD}^{10}$ whereas Lasri et al. detected metallic Fe upon chemical lithiation of $\mathrm{Fe}_{0.5} \mathrm{TiOPO}_{4}$ using Mössbauer spectroscopy. ${ }^{9}$ However, all studies could not explain the source for the specific charge of this family of materials.

In this manuscript we elucidate the reaction mechanism of $\mathrm{Cu}_{0.5} \mathrm{TiOPO}_{4}$ by combining electrochemical information with information from XRD, XAS, NMR, and EDX.

\section{Experimental}

$\mathrm{Cu}_{0.5} \mathrm{TiOPO}_{4}$ was prepared by a co-precipitation method published recently. ${ }^{11}$ The synthesis results in micron-sized particles of both polymorphs, $\alpha$ - and $\beta-\mathrm{Cu}_{0.5} \mathrm{TiOPO}_{4}$ with some percentage of $\mathrm{Cu}_{3}\left(\mathrm{PO}_{4}\right)_{2}$ as impurities.

For electrochemical studies (at $25 \pm 0.1{ }^{\circ} \mathrm{C}$ ), the working electrodes were prepared in three different ways: (1) a $9: 1$ mixture of the powders of $\mathrm{Cu}_{0.5} \mathrm{TiOPO}_{4}$ and Super-P carbon, (2) a self-standing film or (3) a dried slurry doctor-bladed on a copper-foil current collector. Both, the film and the slurry consisted of the $\mathrm{Cu}_{0.5} \mathrm{TiOPO}_{4}$ active material, Super-P carbon conductive additive, and Kynarflex® 2801 binder with a composition of $70: 10: 20 \mathrm{wt} \%$ for the film and $80: 10: 10 \mathrm{wt} \%$ for the slurry, respectively. Coin-like electrochemical cells with a lithium metal counter electrode, a glass fiber separator, and a $1: 1$ mixture of ethylene carbonate and dimethyl carbonate with $1 \mathrm{M} \mathrm{LiPF}_{6}$ as the electrolyte were assembled in an argon-filled glove box. The film was used for in situ XRD and EDX measurements. The electrodes on copper-foil were used for the GITT and NMR measurements. If not stated otherwise a specific current of $42.2 \mathrm{~A} \mathrm{~kg}^{-1}$ with respect to the active material was used. For the GITT measurement, the current was applied for $20 \mathrm{~min}$ followed by a relaxation period of $10 \mathrm{~h}$. Ex situ samples 
for XRD and XAS measurements were cycled with a current density of $14.07 \mathrm{~A} \mathrm{~kg}^{-1}$ and for NMR measurements at $4.22 \mathrm{~A} \mathrm{~kg}^{-1}$.

X-ray diffraction (XRD) measurements were performed at room temperature with a PANalytical Empyrean diffractometer using copper or molybdenum $\mathrm{K}_{\alpha}$-radiation. In situ measurements were performed in a cell with a beryllium window in Bragg-Brentano geometry. Ex situ samples were measured in capillaries.

X-ray absorption spectroscopy (XAS) measurements were performed at the SuperXAS beamline at SLS (PSI, Villigen, Switzerland). In an argon-filled glove box, the cycled powder was filled in capillaries $(d=0.7 \mathrm{~mm})$ and sealed. As reference samples, $\mathrm{CuO}, \mathrm{Cu}_{2} \mathrm{O}, \mathrm{TiO}_{2}$ (rutile), $\mathrm{Li}_{4} \mathrm{Ti}_{5} \mathrm{O}_{12}, \mathrm{Ti}_{2} \mathrm{O}_{3}$, and $\mathrm{TiO}$ were used. Except for $\mathrm{Ti}_{2} \mathrm{O}_{3}$ and TiO, pellets of the reference powder mixed with cellulose were pressed and measured. The other two reference samples were measured undiluted in capillaries. Fluorescence spectra were recorded at the titanium K-edge (except for the titanium foil reference which was measured in transmission) and transmission spectra were recorded at the copper K-edge. For the analysis of the data, the software-package Demeter was used. ${ }^{12}$ For all data, the background was subtracted and the energy of $\mathrm{E}_{0}$ was set to a fraction (50\%) of the edge step.

For NMR measurements, cells were disassembled in an argon-filled glove box and the electrodes were washed with DMC. Afterwards the powder was scratched from the copper current collector, ground in a mortar, and filled in a $4 \mathrm{~mm}$ solid state NMR rotor. All the spectra were acquired using a $400 \mathrm{MHz}$ (9.4 T) ultrashield Bruker spectrometer equipped with a $4 \mathrm{~mm}$ HX MAS probe. ${ }^{31} \mathrm{P}$ single excitation with an Rf field of $125 \mathrm{kHz}$ and a $84745 \mathrm{~Hz}$ spectral width was used to record the spectra.

For EDX measurements, cells were disassembled in an argon-filled glove box. The lithium electrodes were washed in DMC and afterwards placed on an SEM holder. The sample was transferred under vacuum to the SEM (Ultra55 by Carl Zeiss).

\section{Results and discussion}

GITT measurements can give indications on the type of reaction of a material upon lithiation and delithiation; with small overpotentials the reaction is most likely an insertion reaction, with

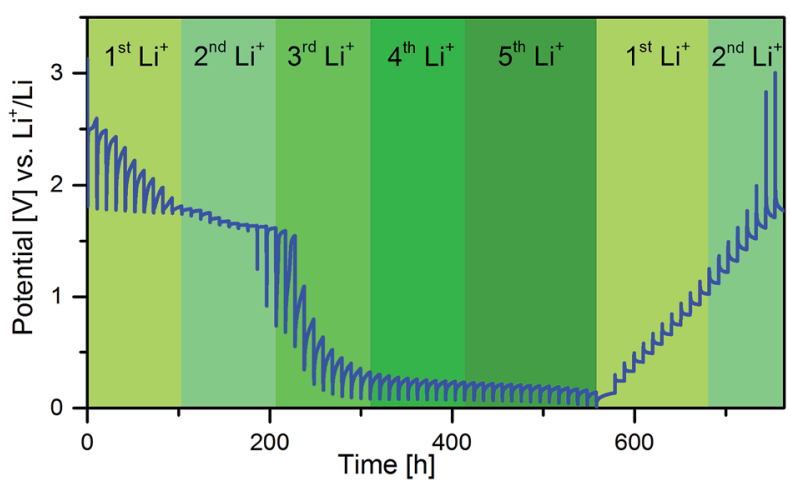

Fig. 1 GITT-measurement during the first cycle of $\mathrm{Cu}_{0.5} \mathrm{TiOPO}_{4}$. high overpotentials the reaction is most likely a conversion reaction. Fig. 1 shows a GITT measurement of an electrode with $\mathrm{Cu}_{0.5} \mathrm{TiOPO}_{4}$ in the first cycle. The lithiation can be separated into four parts corresponding to the amount of $\mathrm{Li}^{+}$per $\mathrm{f}$. $\mathrm{u}$. reacted: $\left(0-1 \mathrm{Li}^{+}\right)$high overpotential, $\left(1-2 \mathrm{Li}^{+}\right)$low overpotential, $\left(2-3 \mathrm{Li}^{+}\right)$high overpotential, and $\left(>3 \mathrm{Li}^{+}\right)$medium overpotential. From these data it can be assumed that the reaction with the first $\mathrm{Li}^{+}$per $\mathrm{f}$. $\mathrm{u}$. is a conversion or extrusion reaction, while the second one is an insertion reaction, followed by a conversion reaction.

The evolution of phases occurring during cycling between $3.0 \mathrm{~V}$ and $1.0 \mathrm{~V}$ for the first cycle and between $3.0 \mathrm{~V}$ and $10 \mathrm{mV}$ during the second cycle was followed by in situ XRD (Fig. 2). At the end of the first plateau after a reaction with approx. $1 \mathrm{Li}^{+}$per f. $u$., reflections of $\mathrm{Cu}_{0.5} \mathrm{TiOPO}_{4}$ change to a similar phase and at the position of the copper 111-reflection $\left(43.3^{\circ}\right)$ a broad peak appears. Upon further cycling to $1.0 \mathrm{~V}\left(\approx 2 \mathrm{Li}^{+}\right.$per f. $\mathrm{u}$.), the reflection of the copper gets more pronounced and the phase similar to $\mathrm{Cu}_{0.5} \mathrm{TiOPO}_{4}$ changes slightly again. This change is reversible upon delithiation to $3.0 \mathrm{~V}$. The following lithiation to $10 \mathrm{mV}$ leads to amorphisation of the structure, with the exception of copper. Upon following delithiation, the copper peak shifts slightly to higher angles (to $43.45^{\circ}$ ).

In order to get a clearer view on the reaction mechanism, samples were cycled to key positions in the galvanostatic curve and ex situ XRD measurements were performed on these samples (Fig. 3). After the lithiation with $1 \mathrm{Li}^{+}$per f. u. (sample c), two main phases can be detected, namely (triclinic) $\mathrm{LiTiOPO}_{4}$ and metallic copper (for the refinement see ESI, Fig. S1 $\dagger$ ). Reflections around $10^{\circ}$ are most likely due to remainders of the electrolyte salt. Upon the reaction with the second $\mathrm{Li}^{+}$per $\mathrm{f}$. $\mathrm{u}$. (sample e), a similar phase to $\mathrm{LiTiOPO}_{4}$ is formed. This phase was not yet reported in the literature. Delithiation to $3.0 \mathrm{~V}$ (sample g) leads back to $\mathrm{LiTiOPO}_{4}$. Lithiation to more negative potentials leads, as for the in situ measurements, to amorphization of the material (sample h) indicating a conversion type reaction which is not reversible (sample $\mathrm{k}$ ). Upon lithiation to $10 \mathrm{mV}$ the reflections of copper do not change significantly;

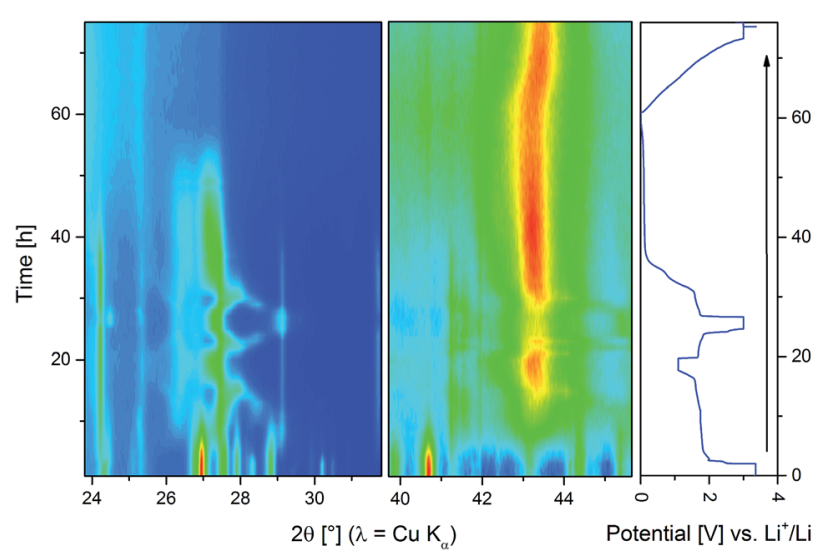

Fig. 2 Contour plot of an in situ XRD measurement at a specific current of $16.9 \mathrm{~A} \mathrm{~kg}^{-1}$ (blue: low intensity; red: high intensity). On the right hand side, the corresponding galvanostatic curve is shown. 

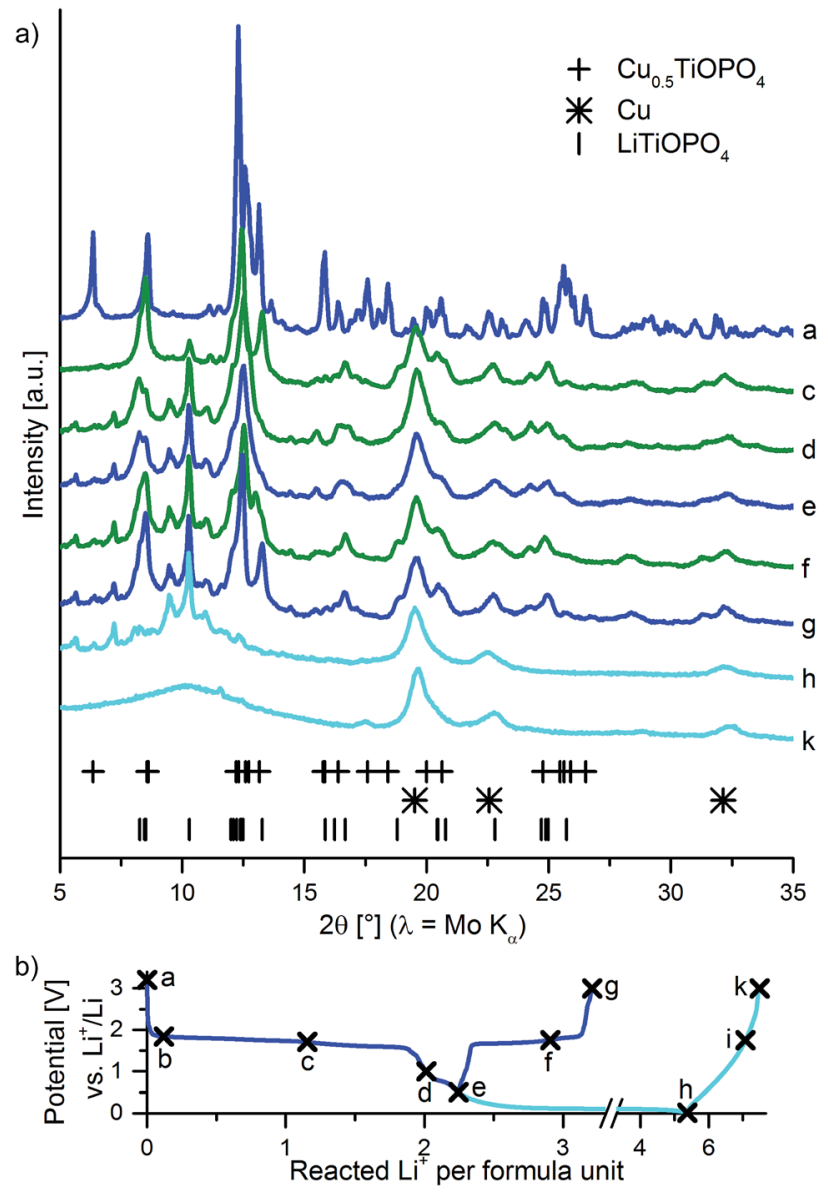

Fig. 3 (a) Ex situ XRD measurements of $\mathrm{Cu}_{0.5} \mathrm{TiOPO}_{4}$ cycled to key points in the first cycle. (b) shows the corresponding galvanostatic curve.

upon delithiation to $3.0 \mathrm{~V}$ they shift slightly to higher angles (from 19.5 to $19.6^{\circ}$ ). This shift of the copper reflection is reversible (ESI, Fig. S2 $\dagger$ ).

The reason for the shift of the copper reflection is unclear yet. Two hypotheses could explain this behavior: (1) copper is extruded as small particles (crystallite size $\approx 6 \mathrm{~nm}$ from an analysis based on the Scherrer-equation). These particles are stuck at phase boundaries between grains of the now amorphous $\mathrm{LiTiOPO}_{4}$. Delithiation might lead to an expansion of those grains which then compress the copper particles in between. (2) At elevated temperatures, an existence of a solid solution of lithium in copper with up to 20 at\% lithium is possible. ${ }^{13}$ This could possibly happen to nanoparticles as well. The change of the lattice constant reported by Klemm and Volavšek $^{13}$ matches with the change we observed. The weak scattering of X-rays by lithium and the small change in the lattice constant might be the reason why this reaction is not seen in the EXAFS data. Note that with the techniques we have at hand, it is not possible to distinguish between both hypotheses. Though we think that (2) is more likely.

The extrusion of copper can also be confirmed by EXAFS measurements at the copper K-edge performed on the same samples of the ex situ XRD measurements. As shown in Fig. 4,

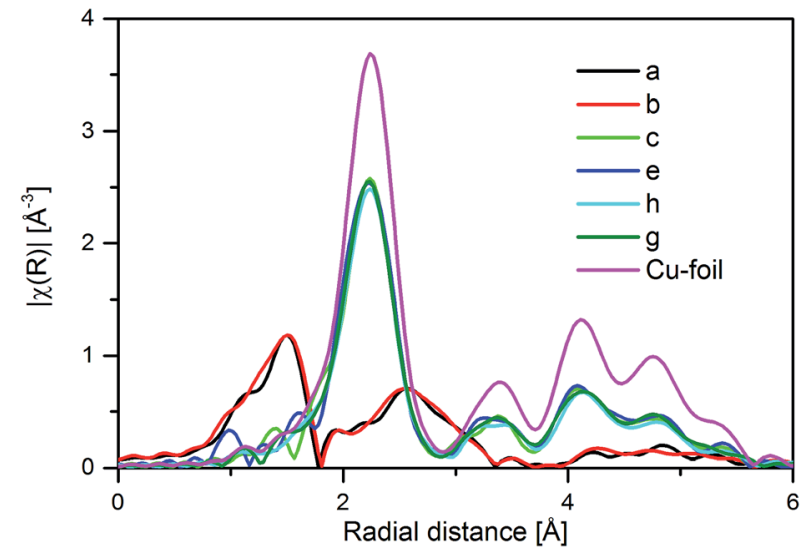

Fig. 4 Fourier transform of the recorded EXAFS-spectra of cycled samples of $\mathrm{Cu}_{0.5} \mathrm{TiOPO}_{4}$ (for labeling see Fig. 6).

$\mathrm{Cu}_{0.5} \mathrm{TiOPO}_{4}$ lithiated to $1.78 \mathrm{~V}$ (before the first plateau) is similar to the starting material while all other samples (starting from the sample $\mathrm{c}$, which was lithiated to $1.71 \mathrm{~V}\left(\approx 1 \mathrm{Li}^{+}\right.$per f. u.) up to sample g, which was delithiated to $3.0 \mathrm{~V}$ ) show a similar spectrum to a metallic copper foil. This indicates that copper is irreversibly extruded from $\mathrm{Cu}_{0.5} \mathrm{TiOPO}_{4}$ during the reaction with the first $\mathrm{Li}^{+}$per $\mathrm{f}$. $\mathrm{u}$. and is extruded as agglomerates of metallic copper. This is also supported by the fitting of the data with the possible scattering pathways (ESI, Fig. S3 and Table S1 $\uparrow$ ). While the pristine sample and the sample cycled to $1.78 \mathrm{~V}$ could be fitted with $\alpha-\mathrm{Cu}_{0.5} \mathrm{TiOPO}_{4}$, the sample cycled to $1.71 \mathrm{~V}$ could only be fitted with metallic copper.

In order to identify the reacting atoms responsible for the different plateaus, ex situ XAS spectra at the titanium and copper K-edges were recorded from samples cycled to key points in the first cycle (Fig. 5). Fig. 6 shows the change of the copper and titanium absorption edges upon lithiation and delithiation of $\mathrm{Cu}_{0.5} \mathrm{TiOPO}_{4}$. The analysis of this change gives another evidence that copper is irreversibly reduced from $\mathrm{Cu}^{2+}$ to $\mathrm{Cu}^{0}$ between 1.78 and $1.71 \mathrm{~V}$ upon lithiation (between samples $\mathrm{b}$ and c). The analysis of the titanium K-edge shows that titanium is reversibly reduced in the plateau between 1.71 and $1.0 \mathrm{~V}$ (samples c to d) from $\mathrm{Ti}^{4+}$ to $\mathrm{Ti}^{3+}$. Upon further lithiation from 0.5 to $0.01 \mathrm{~V}$ (samples e to $\mathrm{h}$ ), titanium is reduced further to an oxidation state below $2+$. In both cases, upon cycling to $0.01 \mathrm{~V}$ and $0.5 \mathrm{~V}$, the reduction of the titanium is reversible; upon delithiation to $3.0 \mathrm{~V}$, it is oxidized to $\mathrm{Ti}^{4+}$ again.

To which oxidation state titanium was reduced upon lithiation to $0.01 \mathrm{~V}$ is not completely clear by the XANES data due to two reasons: (1) the position of the absorption edge can not only shift due to a reduction of a species but also due to changes in the coordination of the sample. Since at this stage of the cycling the sample turns amorphous, there are certainly major structural changes. If these changes affect the coordination of the titanium, this cannot be distinguished from a change in the oxidation state using XANES measurements. Calculations by "materialsproject.org"14,15 show for the isostructural $\mathrm{Ni}_{0.5} \mathrm{TiOPO}_{4}$ and $\mathrm{Fe}_{0.5} \mathrm{TiOPO}_{4}$ that thermodynamically both titanium and the phosphate group can be reduced upon 

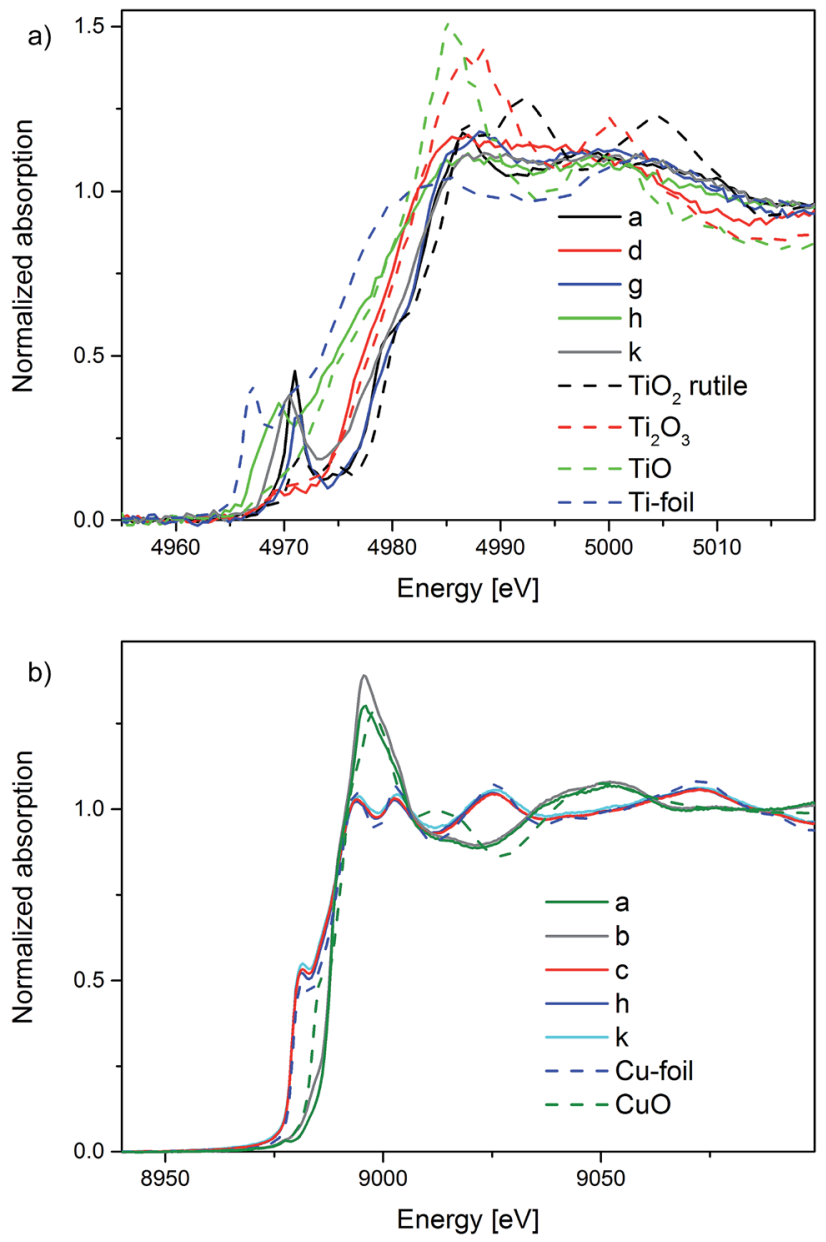

Fig. 5 Selected normalized XAS spectra at (a) the titanium and (b) the copper K-edge (for labeling see Fig. 6).

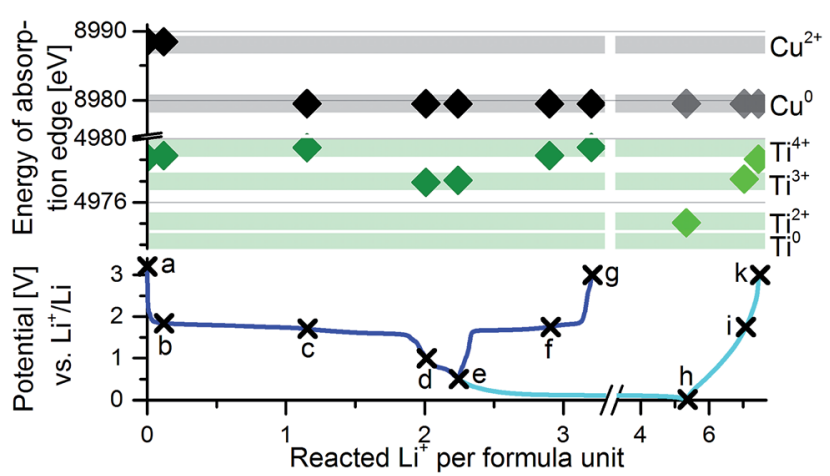

Fig. 6 Change of the energy of the copper- and the titanium absorption edge at half of the edge step of ex situ samples of $\mathrm{Cu}_{0.5} \mathrm{TiOPO}_{4}$. The position of the absorption edge of the measured reference materials is shown as well. At the bottom, the corresponding galvanostatic curve is plotted.

lithiation to $0.01 \mathrm{~V}$. (2) Relaxation effects could be the consequence of a partial re-oxidation of the ex situ sample, e.g. by a reaction with other components present in the cell like electrolyte and/or the SEI.

Ex situ ${ }^{31} \mathrm{P}$ MAS NMR measurements can help to elucidate whether phosphate is reduced upon lithiation to $0.01 \mathrm{~V}$ or not.
Fig. 7a shows the ${ }^{31} \mathrm{P}$ NMR spectrum of $\mathrm{Cu}_{0.5} \mathrm{TiOPO}_{4}$ as synthesized; due to the paramagnetism of $\mathrm{Cu}^{2+}$, the chemical shift range is larger than usual ${ }^{31} \mathrm{P}$ NMR, starting from $-200 \mathrm{ppm}$ to $+500 \mathrm{ppm}$. We can distinguish two peaks, one being at $429 \mathrm{ppm}$ assigned to the phosphorus nucleus in $\mathrm{Cu}_{0.5} \mathrm{TiOPO}_{4}$ and one at $28 \mathrm{ppm}$ assigned to $\mathrm{Cu}_{3}\left(\mathrm{PO}_{4}\right)_{2}$ (impurity detected by XRD in the as-synthesized compound). Starting from this material, NMR spectra were acquired at different cycled points in the galvanostatic curve (Fig. 7(a)-(e)). At the last point, where the potential is back to $3.0 \mathrm{~V}$ and therefore at the end of the cycle, one single peak is observed (Fig. 7e) at $11 \mathrm{ppm}$ assigned to $\mathrm{Li}_{3} \mathrm{PO}_{4}$ (according to the measurement of a commercial powder, Fig. 7f) meaning that the initial $\mathrm{Ti}^{3+}$ is reduced and is not part of the final ${ }^{31} \mathrm{P}$ compound.

In the fully lithiated state at $0.01 \mathrm{~V}$, one single peak is observed (Fig. 7d) at $11 \mathrm{ppm}$ assigned to $\mathrm{Li}_{3} \mathrm{PO}_{4}$ (Fig. 7f) meaning that the phosphate group was not reduced at these potentials. The $\mathrm{Li}_{3} \mathrm{PO}_{4}$ does not change upon delithiation to $3.0 \mathrm{~V}$ (Fig. 7e). Note that when the irreversible reduction of $\mathrm{Cu}^{2+}$ to $\mathrm{Cu}^{0}$ happens, a ${ }^{31} \mathrm{P}$ containing intermediate is formed (Fig. 7b). Two sharp peaks at respectively -3 and $-9 \mathrm{ppm}$ appeared at a potential of $1.75 \mathrm{~V}$ and disappear below $1.5 \mathrm{~V}$.

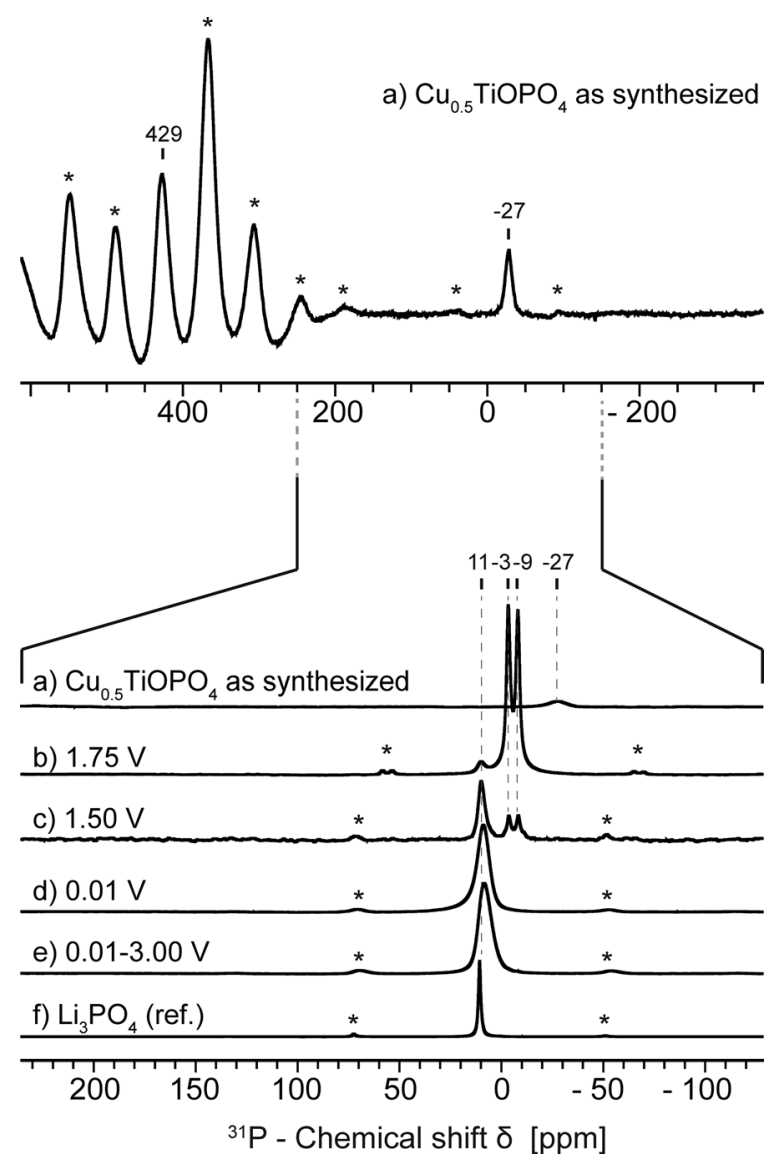

Fig. $7{ }^{31} \mathrm{P}$ MAS NMR spectra of ex situ samples of $\mathrm{Cu}_{0.5} \mathrm{TiOPO}_{4}$ and pure $\mathrm{Li}_{3} \mathrm{PO}_{4}$. The top spectrum is an addition of two spectra acquired at two different transmitter positions ( 0 ppm and $250 \mathrm{ppm}$ ) to cover a larger window width. For all the spectra the number of scans was $512 \mathrm{~K}$ and the recycling delay was set to $1 \mathrm{~s}$. 
Those two peaks are assigned to $\mathrm{LiTiOPO}_{4}$ in the triclinic phase. To confirm this hypothesis NMR CASTEP ${ }^{\mathbf{1 6}}$ calculations were carried out on the $\mathrm{LiTiOPO}_{4}$ in the triclinic and orthorhombic phase. The results were referenced with respect to triphenyl phosphine (ESI, Fig. S3†). The triclinic phase gave two signals (5 ppm apart from each other) with equal intensity while the orthorhombic gave only one signal at different chemical shifts (ESI, Table S2 $\dagger$ ). Experimentally the two peaks are separated by $6 \mathrm{ppm}$ and have the same intensities. This confirms the presence of the triclinic phase at a potential of $1.75 \mathrm{~V}$.

This excludes the possibility that phosphate is reduced upon lithiation to $0.01 \mathrm{~V}$, leaving only two further components in the electrochemical system to be reduced between 0.5 and $0.01 \mathrm{~V}$ : the conductive additive Super- $\mathrm{P}$ and $\mathrm{Ti}^{3+}$. Additional experiments, with electrodes that contained only Super-P carbon as the active material, showed that Super-P carbon exhibits a specific charge of $574 \mathrm{~A} \mathrm{~h} \mathrm{~kg}^{-1}$ in the first lithiation (including the formation of an SEI). Based on the $10 \%$ content of Super-P in the electrode, the total reaction of $\mathrm{Cu}_{0.5} \mathrm{TiOPO}_{4}\left(\approx 5.4 \mathrm{Li}^{+}\right.$per f. u.) is thus by $<0.5 \mathrm{Li}^{+}$per $\mathrm{f}$. $\mathrm{u}$. less than it seems to be, and cannot explain the reaction with $\approx 3 \mathrm{Li}^{+}$per $\mathrm{f}$. $\mathrm{u}$. between 0.5 and $0.01 \mathrm{~V}$. This indicates together with the results from XANES that titanium is reduced from $\mathrm{Ti}^{3+}$ at these potentials at least to $\mathrm{Ti}^{2+}$, most likely further. The rest of the specific charge could be explained by the reduction of the electrolyte on newly exposed surfaces, i.e. SEI formation type reactions.

The irreversible nature of the reduction of $\mathrm{Cu}^{2+}$ to $\mathrm{Cu}^{0}$ upon cycling at potentials negative to $3.0 \mathrm{~V}$ is obvious because metallic copper is not noticeably oxidized at these potentials (e.g. the copper current collector). Experiments on self-standing films of $\mathrm{Cu}_{0.5} \mathrm{TiOPO}_{4}$ without a copper current collector show that the reduced copper can be re-oxidized electrochemically (Fig. 8). However, the re-oxidation is not complete and the material shows a very strong capacity fading (almost no reaction detectible after 3 cycles).

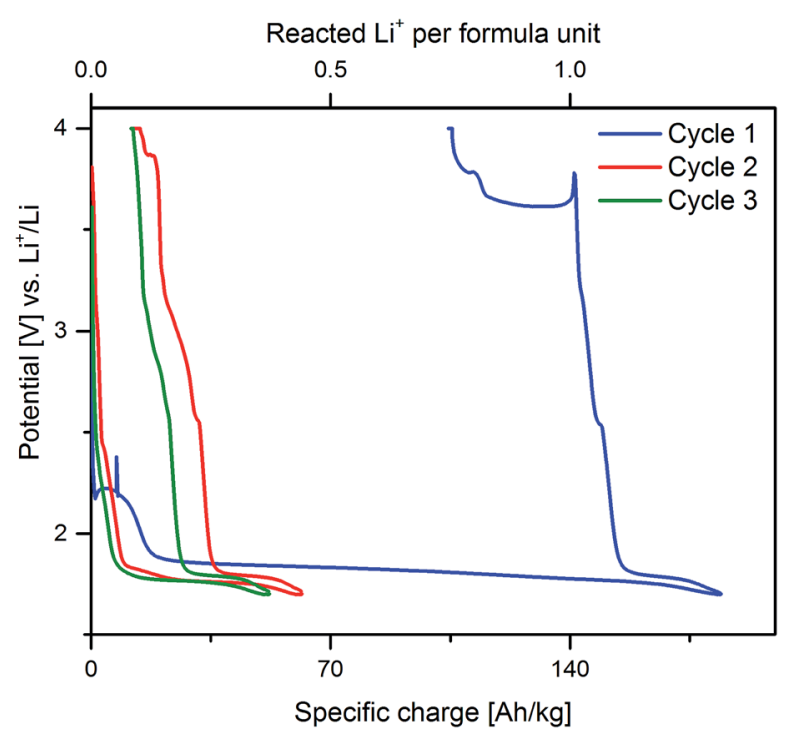

Fig. 8 Galvanostatic curve of $\mathrm{Cu}_{0.5} \mathrm{TiOPO}_{4}$ cycled 3 times between $1.7 \mathrm{~V}$ and $4.0 \mathrm{~V}$ with a specific current of $14.06 \mathrm{~A} \mathrm{~kg}^{-1}$.

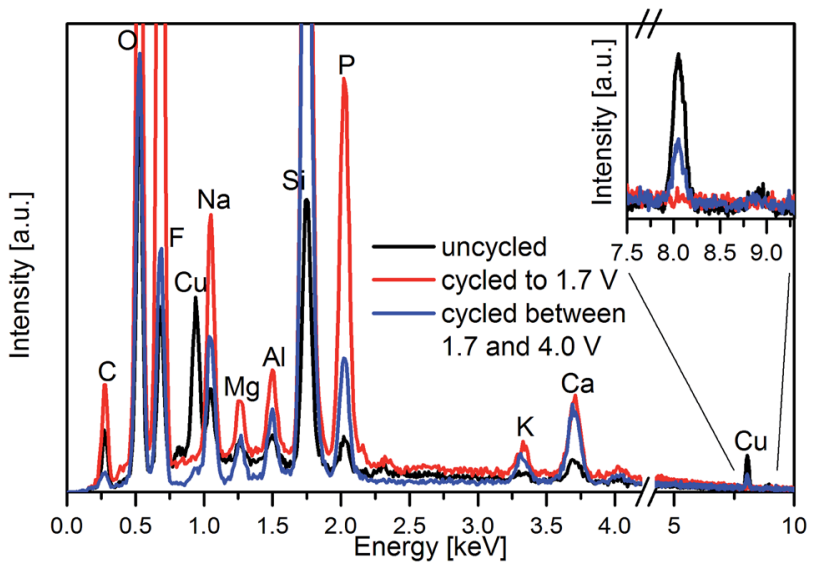

Fig. 9 EDX spectra of lithium counter electrodes and working electrodes of $\mathrm{Cu}_{0.5} \mathrm{TiOPO}_{4}$ after cycling to $1.7 \mathrm{~V}$, cycling 10 times between $1.7 \mathrm{~V}$ and $4.0 \mathrm{~V}$, and an uncycled cell (all stored for two weeks after assembly).

The explanation for this behavior can be found by EDX measurements on the lithium counter-electrode of these cells (Fig. 9). Copper can be detected on lithium after cycling to $4.0 \mathrm{~V}$ after prior cycling to $1.7 \mathrm{~V}$ but not after solely cycling to $1.7 \mathrm{~V}$. Since the only possible source of copper in the complete system was $\mathrm{Cu}_{0.5} \mathrm{TiOPO}_{4}$, the copper must be dissolved, probably as $\mathrm{Cu}^{2+}$, upon oxidation in the electrolyte and was then reduced on metallic lithium. Measurements of the counter electrode of an uncycled cell of $\mathrm{Cu}_{0.5} \mathrm{TiOPO}_{4}$ showed that also copper ions from the starting compound are dissolved at least partly in the electrolyte within two weeks and are then reduced at the lithium counter electrode. Note that impurities from $\mathrm{Na}, \mathrm{Mg}, \mathrm{Al}, \mathrm{K}$, and Ca might come from washing the lithium in a glass beaker with DMC.

\section{Conclusions}

Based on the results above, a reaction mechanism is suggested as summarized in Table 1 where the different reaction steps of $\mathrm{Cu}_{0.5} \mathrm{TiOPO}_{4}$ upon lithiation and delithiation are shown. The extrusion and reduction of copper could be detected by XRD, XANES, and EXAFS. The re-oxidation of copper was shown indirectly by electrochemical methods combined with EDX. The

Table 1 Reaction scheme of $\mathrm{Cu}_{0.5} \mathrm{TiOPO}_{4}$ in the first lithiation and delithiation cycle

\begin{tabular}{|c|c|c|c|c|}
\hline & & Potential & Reaction & Type \\
\hline \multirow[t]{3}{*}{$\begin{array}{l}\text { Lithiation/ } \\
\text { reduction }\end{array}$} & $1^{\mathrm{st}} \mathrm{Li}$ & $1.75 \mathrm{~V}$ & $\mathrm{Cu}^{2+} \rightarrow \mathrm{Cu}^{0}$ & $\begin{array}{l}\text { Conversion } \\
\text { (extrusion) }\end{array}$ \\
\hline & $2^{\text {nd }} \mathrm{Li}$ & $1.70 \mathrm{~V}$ & $\mathrm{Ti}^{4+} \rightarrow \mathrm{Ti}^{3+}$ & Insertion \\
\hline & $3^{\text {rd }} \mathrm{Li}$ & $\approx 0.1 \mathrm{~V}$ & $\mathrm{Ti}^{3+} \rightarrow \mathrm{Ti}^{2+}$ & Conversion \\
\hline \multirow{3}{*}{$\begin{array}{l}\text { Delithiation/ } \\
\text { re-oxidation }\end{array}$} & $1^{\text {st }} \mathrm{Li}$ & $<1.0 \mathrm{~V}$ & $\mathrm{Ti}^{3+} \rightarrow \mathrm{Ti}^{2+}$ & Conversion \\
\hline & $2^{\text {nd }} \mathrm{Li}$ & $1.75 \mathrm{~V}^{a}$ & $\mathrm{Ti}^{4+} \rightarrow \mathrm{Ti}^{3+}$ & Insertion $^{a}$ \\
\hline & $3^{\mathrm{rd}} \mathrm{Li}$ & $>3.5 \mathrm{~V}$ & $\begin{array}{l}\mathrm{Cu}^{0} \rightarrow \mathrm{Cu}^{2+} \\
\text { (dissolved) }\end{array}$ & Conversion \\
\hline
\end{tabular}

${ }^{a}$ Potential and reaction type given for lithiation to $2 \mathrm{Li}^{+}$per $\mathrm{f}$. $\mathrm{u}$. 
reduction and oxidation of titanium was shown by XANES, taking into consideration the not changing $\mathrm{PO}_{4}{ }^{3-}$ measured by ${ }^{31} \mathrm{P}$ MAS NMR. The reduction from $\mathrm{Ti}^{4+}$ to $\mathrm{Ti}^{3+}$ is an insertion reaction; further reductions take place in conversion processes.

\section{Acknowledgements}

Swiss National Science Foundation is thanked for financial support. Dr Olga Safonova from the SuperXAS beamline at SLS (Villigen, Switzerland) is thanked for the support during the measurements.

\section{References}

1 I. Belharouak and K. Amine, Electrochem. Commun., 2005, 7, 648.

2 H. M. Hollmark, K. Maher, I. Saadoune, T. Gustafsson, K. Edström and L. C. Duda, Phys. Chem. Chem. Phys., 2011, 13, 6544 .

3 K. Maher, K. Edström, I. Saadoune, T. Gustafsson and M. Mansori, J. Power Sources, 2011, 196, 2819.

4 V. A. Godbole, C. Villevieille, H.-H. Sommer, J.-F. Colin and P. Novák, Electrochim. Acta, 2012, 77, 244.

5 R. Essehli, B. El Bali, A. Faik, S. Benmokhtar, B. Manoun, Y. Zhang, X. J. Zhang, Z. Zhou and H. Fuess, J. Alloys Compd., 2012, 530, 178.

6 K. Lasri, M. Dahbi, A. Liivat, D. Brandell, K. Edström and I. Saadoune, J. Power Sources, 2013, 229, 265.
7 R. Eriksson, K. Maher, I. Saadoune, M. Mansori, T. Gustafsson and K. Edström, Solid State Ionics, 2012, 225, 547.

8 R. Essehli, B. El Bali, H. Ehrenberg, I. Svoboda, N. Bramnik and H. Fuess, Mater. Res. Bull., 2009, 44, 817.

9 K. Lasri, I. Saadoune, Y. Bentaleb, D. Mikhailova, H. Ehrenberg, L. Häggström and K. Edström, Solid State Ionics, 2012, 224, 15.

10 R. Essehli, B. E. Bali, H. Ehrenberg, I. Svoboda, N. Bramnik and H. Fuess, Mater. Res. Bull., 2009, 44, 817.

11 P. Bleith, P. Novák and C. Villevieille, J. Electrochem. Soc., 2013, 160, A1534.

12 B. Ravel and M. Newville, J. Synchrotron Radiat., 2005, 12, 537.

13 W. Klemm and B. Volavšek, Z. Anorg. Allg. Chem., 1958, 296, 184.

14 A. Jain, S. P. Ong, G. Hautier, W. Chen, W. D. Richards, S. Dacek, S. Cholia, D. Gunter, D. Skinner, G. Ceder and K. A. Persson, APL Mater., 2013, 1, 011002.

15 F. Zhou, M. Cococcioni, C. A. Marianetti, D. Morgan and G. Ceder, Phys. Rev. B: Condens. Matter Mater. Phys., 2004, 70, 235121.

16 S. J. Clark, M. D. Segall, C. J. Pickard, P. J. Hasnip, M. J. Probert, K. Refson and M. C. Payne, Z Kristallogr, 2005, 220, 567. 